\title{
AVALIAÇÃO DA QUALIDADE DAS ÁGUAS NA MICROBACIA HIDROGRÁFICA DOS CÓRREGOS GAVANHERY E LAMBARI NO MUNICÍPIO DE GETULINA, SP
}

\author{
WATER QUALITY EVALUATION IN \\ MICROWATERSHED OF THE GAVANHERY AND \\ LAMBARI STREAMS \\ (GETULINA, SÃO PAULO STATE, BRAZIL) \\ GETULINA TOWN, SP
}

\section{Francisco Rodrigues Junior ${ }^{1}$, Sérgio Luis de Carvalho}

\author{
${ }^{1}$ Mestre em Engenharia Civil, UNESP / FEIS-PPGEC, Ilha Solteira, SP \\ Rua Júlio Prestes, 553, centro, Cep 16.450-000 - Getulina - SP - Fone -14-3552 2228 \\ e-mail: frjgetulina@yahoo.com.br \\ ${ }^{2}$ Prof. Dr. - Departamento de Biologia e Zootecnia - Unesp - Campus Ilha Solteira-SP \\ Passeio Monção, 226, Zona Norte, Cep 15.385-000 Ilha Solteira - SP - e-mail: \\ sergicar@bio.feis.unesp.br
}

\section{RESUMO}

O trabalho teve como objetivo avaliar a qualidade da água na Microbacia Hidrográfica dos Córregos Gavanhery e Lambari, no Município de Getulina, Estado de São Paulo, no período de maio a outubro de 2007, e o seu estado de degradação associado à utilização da área de entorno. Mensalmente, foram coletadas amostras em sete pontos da Microbacia, e realizados ensaios de parâmetros físico-químicos e biológicos. Os resultados dos valores de IQA, associados com observações feitas in loco, permitiram avaliar a qualidade da água e confirmar o atual estado de degradação desta bacia hidrográfica, manifestado por erosão, inexistência de mata ciliar, assoreamento, elevação dos teores de elementos fertilizantes (fósforo e nitrogênio) e aumento dos níveis de concentrações de coliformes fecais e totais em alguns pontos analisados. Constatou-se que a poluição dos Córregos Gavanhery e Lambari foi alta em alguns períodos do ano, levando-os a valores inferiores aos de um rio de Classe 2 (nos pontos 2, 3 e principalmente no Ponto " 5 "), situado no meio urbano com qualidade da água considerada "Ruim", enquanto que os demais pontos $(1,3,6$ e 7) se enquadram na classificação apenas “Aceitável”.Tais observações 
exigem medidas de correção e mitigação nos locais mais afetados, e um manejo sustentável que permita a conservação de toda a microbacia estudada.

Palavras-chave: IQA. Degradação. Microbacia. Córrego Gavanhery. Córrego Lambari

\begin{abstract}
The work had as objective to monitoring and analyzing the water quality of the microwatershed of Gavanhery and Lambari streams, in Getulina town, Sao Paulo State, in the period between may and october of 2007, and its degradation stage in association to the utilization of the surrounding area. Monthly, water samples were collected in seven points of this microwatershed, and some of its physical, chemical and biological parameters were analyzed that allowed to calculate the WQI - Water Quality Index. Gavanhery an Lambari streams were both located in the periphery of the municipal district, and receive waters from clandestine domestic sewers and from superficial pluvial waters. The WQI results, in addition to observations in loco, also made possible to evaluate the water quality and check the actual degradation stage of this hidrographic basin, manifested by erosion, the ciliary forest nothingness, increase on the number of factors for fertilizers (phosphorus and nitrogen) and the increase of the concentration levels of the fecal coliforms and total, in some analyzed points. Went verifyd that the pollution in Gavanhery and Lambari streams was kept in high level in some periods of the year, so its numbers are lower than a Class II level river (at points 2, 3 but especially at Point " 5 "), located at the urban environment, where the water quality is considered "Bad". For points 1, 3, 6 and 7 the water quality is considered "Acceptable", requesting correction measures and mitigation in the most affected places, and a maintainable handling that allows for the microbasin conservation.
\end{abstract}

Keywords: IQA. Environmental degradation. Watershed. Gavanhery Stream. Lambari Stream.

\title{
1. INTRODUÇÃO
}

Segundo Basso e Carvalho (2007), nos últimos anos, em conseqüência do aumento e da diversificação das atividades antrópicas em todo o mundo, a exploração dos recursos naturais passou a ser muito intensa, gerando problemas de degradação dos recursos naturais. Esta deterioração inviabiliza a utilização de parte dos recursos, entre eles a água, que se constitui um dos mais importantes, por ser essencial à vida de todos os seres que habitam a Terra, incluindo o homem. Ultimamente o uso dos recursos naturais disponíveis no mundo aumentou com as atividades antrópicas e seus 
diversos modos de utilização, principalmente em relação aos recursos hídricos das bacias hidrográficas (TUNDISI, 2003).

Os ecossistemas aquáticos acabam de uma forma ou de outra, servindo como reservatórios temporários ou finais de grande variedade e quantidade de poluentes descartados no ar, no solo ou diretamente nos corpos de água. Desta forma, a poluição do ambiente aquático, provocada pelo homem, de uma forma direta ou indireta, mediante a introdução de substâncias inorgânicas ou orgânicas, produz efeitos deletérios tais como: prejuízo aos seres vivos; perigo à saúde humana; efeitos negativos as atividades aquáticas (pesca, lazer, entre outras) e prejuízo à qualidade da água com respeito ao uso na agricultura, indústria e outras atividades econômicas (MEYBECK e HELMER, 1992).

Segundo Refosco (1996), parte dos efeitos da poluição é neutralizada ou estabilizada pelo corpo receptor, dependendo da proporção da mistura (diluição) e do potencial de estabilização natural das águas. Mas tudo que ultrapassar essa capacidade deverá se eliminada através de tratamento adequado (BRANCO, 1991). A água é um recurso estratégico e um bem comum que deve ser compartilhado por todos. "A água é muito mais do que um recurso natural. Ela é parte integral do nosso planeta. Está presente há bilhões de anos, e atua na dinâmica funcional da natureza" (PIELOU, 1998).

Os recursos naturais pertencentes às bacias hidrográficas são de extrema importância à sociedade, pois é através da utilização destes recursos que a humanidade se beneficia para sua sobrevivência. A distribuição de água no globo e sua aparente inesgotabilidade têm levado a humanidade a tratar este recurso renovável e limitado com descaso, uma vez que tanto a escassez da água, como os excessos em seu consumo, resultam do mau uso dos recursos naturais (CALIJURI e OLIVEIRA, 2000).

O uso inadequado dos solos, o desmatamento irracional e o uso indiscriminado de fertilizantes, corretivos e agrotóxico vêm provocando inúmeros problemas ambientais, principalmente em áreas de nascentes e ribeirinhas, alterando a qualidade e quantidade de água drenada pela bacia hidrográfica (POLETO et al., 2010).

$\mathrm{Na}$ microbacia hidrográfica dos Córregos Gavanhery e Lambari, o impacto antrópico tem se caracterizado pelo lançamento de esgotos clandestinos, tanto urbanos quanto rurais, diretamente nos corpos de água sem nenhum tratamento, falta de práticas de conservação do solo e ausência de matas ciliares.

O objetivo deste trabalho foi avaliar, por meio do Î́ndice de Qualidade da Água (IQA), a qualidade da água da microbacia hidrográfica dos Córregos Gavanhery e Lambari, inseridos nos limites do município de Getulina (SP) e o seu estado de degradação associado à utilização da área de entorno. 


\section{MATERIAL E MÉTODOS}

\subsection{Caracterização da área de estudo}

A área de estudo que compreende a microbacia têm influência direta sobre o Córrego Gavanhery e está inserida no limite do município de Getulina - SP, o qual se localiza na Região Centro Oeste do Estado de São Paulo. O município de Getulina possui uma área territorial de aproximadamente $675 \mathrm{Km}^{2}$ e uma área urbanizada de aproximadamente $8,40 \mathrm{~km}^{2}$. Segundo dados do IBGE (2000), a população da cidade foi estimada em 10.554 habitantes. A cidade localiza-se a cerca de $470 \mathrm{~km}$ da capital, no centro-oeste do Estado de São Paulo e tem as seguintes coordenadas geográficas:

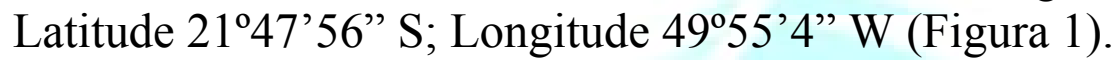

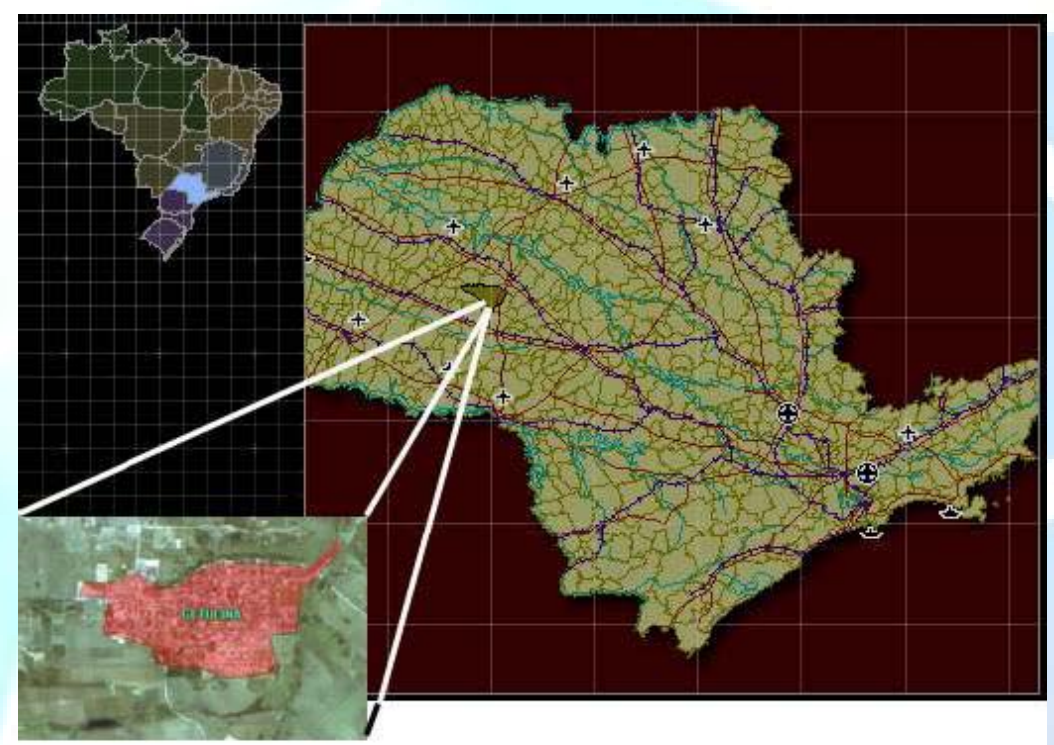

Figura 1. Localização do Município de Getulina no estado de São Paulo Fonte: Adaptado IBGE (2000).

\subsection{Pontos de amostragem}

Para avaliação da qualidade da água foram escolhidos previamente 7 (sete) pontos distintos no decorrer do percurso dos Córregos, sendo seis pontos no Córrego Gavanhery e um ponto no Córrego Lambari. Estes pontos foram escolhidos estrategicamente de forma a caracterizar com melhor precisão os impactos antrópicos causados. Os pontos 1 e 2 estão localizados na nascente dos Córregos Gavanhery e Lambari respectivamente como forma de se obter as características originais das águas dos Córregos. O ponto 3 está localizado no Córrego Gavanhery a aproximadamente $10 \mathrm{~m}$ (dez metros) antes da confluência com o Córrego Lambari, porém dentro do perímetro urbano da cidade, onde o assoreamento é visível. Este ponto foi escolhido devido à influência de grande parte da área urbana através do lançamento de águas pluviais, esgotos clandestinos e resíduos sólidos domésticos. $\mathrm{O}$ ponto 4 está localizado no Córrego Gavanhery a aproximadamente $15 \mathrm{~m}$ (quinze metros) à jusante da confluência com o Córrego Lambari, e embora esteja localizado 
fora do perímetro urbano sofre a sua influência. Este ponto foi escolhido com o objetivo de se determinar a contribuição do Córrego Lambari, uma vez que este em grande parte do seu percurso recebe contribuições de águas pluviais e lançamentos clandestinos de esgoto doméstico do bairro Hilário Penachio e de moradores que construíram suas casas em área de risco.

O ponto 5 está localizado no Córrego Gavanhery, a aproximadamente $15 \mathrm{~m}$ (quinze metros) à jusante do lançamento da Estação de Tratamento de Esgoto (ETE), fora da região urbanizada da cidade de Getulina. Este ponto foi escolhido com objetivo de avaliar a qualidade da água do Córrego Gavanhery, após ter percorrido toda a extensão da região urbanizada e para analisar a influência da ETE sobre este curso de água. O ponto 6 está localizado no Córrego Gavanhery, bem a jusante do lançamento da ETE, fora da região urbanizada da cidade de Getulina. No entorno deste ponto encontra-se muito gado de corte, pois está dentro de uma propriedade rural, e observa-se também a inexistência de mata ciliar. Este ponto foi escolhido com objetivo de avaliar a qualidade da água do Córrego Gavanhery, após ter percorrido grande parte da região rural.

O ponto 7 está localizado no Córrego Gavanhery na sua posição mais a jusante, no exutório, aproximadamente 10 metros antes de desaguar no Rio Feio, após ter percorrido a região urbana da cidade de Getulina e todos os demais pontos que possivelmente influenciam a qualidade de suas águas. Em seu entorno observa-se uma grande área de mata ciliar. O ponto foi escolhido para que se pudesse avaliar a qualidade da água do Córrego Gavanhery bem como analisar um possível processo de autodepuração no decorrer do seu percurso.

Para cada um dos pontos foram registradas coordenadas geográficas por meio de aparelho GPS. Na Figura 2 observa-se a localização dos pontos de coleta e análise contidas nas delimitações da microbacia do Córrego Gavanhery. A área destacada nesta figura (cor mais escura) é a região compreendida pela área urbana da cidade de Getulina, inserida nas delimitações da microbacia do Córrego Gavanhery.

\subsection{Métodos utilizados}

\subsubsection{Levantamento de Campo (Amostragem)}

Foram realizadas visitas aos locais das investigações, nos pontos onde foram efetuadas as coletas das amostras. Uma vez definidos os pontos de amostragens, foram realizadas visitas nos meses pré-programados para coleta e análise da água dos cursos de água, cujas amostras foram preservadas de acordo com o Guia Técnico de Coleta de Amostras (CETESB, 2004), para a realização dos ensaios. A realização de amostragens nas seis visitas possibilitou a avaliação da dinâmica de funcionamento dos sistemas aquáticos nos períodos de seca e chuva. 


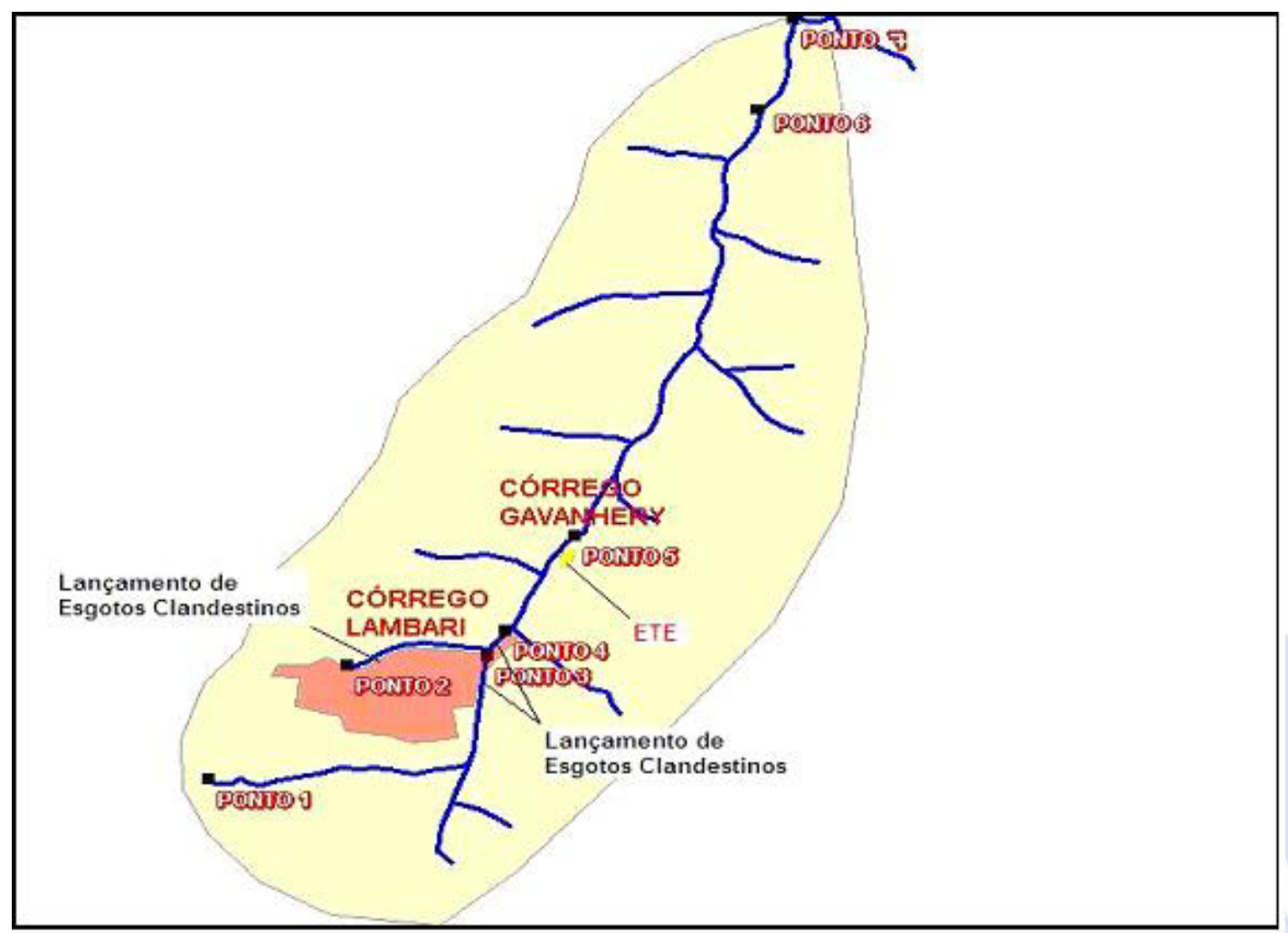

Figura 2. Imagem contendo de forma geral a localização dos 7 pontos definidos para análise da água na Microbacia Hidrográfica do Córrego Gavanhery, Getulina - SP

Fonte: Rodrigues Jr. (2008)

Alguns ensaios foram realizados no próprio local de amostragem, por meio de equipamentos pertencentes ao Laboratório de Análises Químicas e Controle Industrial - LACI. Sendo assim foram analisados diretamente no campo a temperatura $\left({ }^{\circ} \mathrm{C}\right)$, com equipamento analógico, e o $\mathrm{pH}$ da água, com equipamento eletrônico digital, podendo-se obter os dados no próprio local.

Dentro desse processo de coleta de informações em campo, foi ainda verificada a integridade ecológica da vegetação da microbacia, a ocorrência de fontes pontuais de contaminação da água e pontos de degradação do solo, completando dessa forma, o levantamento das condições de cada local da área de estudo.

Foram realizadas 06 (seis) coletas, no período de 6 (seis) meses. Estas tiveram início no mês de Maio de 2007 e término em Outubro de 2007, o que permitiu avaliar possíveis alterações importantes na qualidade da água, dentro de critérios que contemplem as variações nos períodos de chuva e seca. Porém nos dias de coleta e também nos dias que as antecederam não houve chuva.

As amostras eram armazenadas em caixas térmicas, mantendo-se assim as condições ideais para a sua preservação. Para a determinação laboratorial do oxigênio dissolvido - OD (mg. $\left.\mathrm{L}^{-1}\right)$, este foi fixado por meio de ensaio no próprio local da coleta., onde foram adicionados dois reagentes, sendo eles o sulfato manganoso e a ázida sódica. Em seguida o frasco era agitado para ocorrer à reação, após a qual, as amostras eram armazenadas em caixa térmica. 


\subsubsection{Variáveis analisadas}

Considerando-se que a microbacia está localizada no Município de Getulina, para maior facilidade, as análises das amostras foram realizadas no Laboratório de Análises Químicas e Controle Industrial - LACI, pertencente à Fundação Paulista de Tecnologia e Educação. Os relatórios das análises dos ensaios eram disponibilizados aproximadamente 20 dias após cada coleta. Os parâmetros de qualidade da água foram avaliados através dos dados das análises laboratoriais com base nos Métodos para as Análises de Águas Potáveis e Residuárias - Standard Methods - $20^{\circ}$ Edição, método de espectrofotometria de absorção atômica, espectrofotometria no visível. (CLESCERI et al, 1998).

A escolha dos parâmetros analisados foi feita tendo como objetivo o cálculo do IQA, com base em 9 (nove) parâmetros descritos a seguir:

Parâmetros físicos: $\mathrm{pH}$, Turbidez (NTU), Cor $(\mathrm{uH})$, e Temperatura $\left({ }^{\circ} \mathrm{C}\right)$;

Parâmetros químicos: Nitrogênio Total $\left(\mathrm{mg} . \mathrm{L}^{-1}\right)$, Fósforo Total $\left(\mathrm{mg} . \mathrm{L}^{-1}\right)$, Demanda Bioquímica de Oxigênio DBO (mg. $\left.\mathrm{L}^{-1}\right)$, Oxigênio Dissolvido OD (mg.L $\left.\mathrm{L}^{-1}\right)$, Sólidos suspensos totais (mg. $\left.\mathrm{L}^{-1}\right)$.

Parâmetros biológicos: Coliformes Fecais e Totais (NPM/100 ml)

Os dados coletados foram tratados em planilhas eletrônicas de cálculo para geração de gráficos e figuras interessantes à avaliação da qualidade da água.

A temperatura da água $\left({ }^{\circ} \mathrm{C}\right)$ e $\mathrm{o} \quad \mathrm{pH}$ foram analisados pelo método Eletrométrico, por meio de pHmetro de membrana.

As análises de Nitrogênio Total $\left(\mathrm{mg} . \mathrm{L}^{-1}\right)$ foram realizadas por meio de digestão ácida utilizando-se o espectrômetro de absorção atômica, onde foram determinados os nitritos e nitratos organical e amoniacal formando assim o Nitrogênio Total.

A quantidade de OD (mg. $\left.\mathrm{L}^{-1}\right)$ foi determinada através do método de Winkler modificado, por meio de titulador.

A DBO foi determinada pelo Método das diluições, incubado a $20^{\circ} \mathrm{C}$ por período de 5 dias através de titulador.

A quantidade de sólidos suspensos totais $\left(\mathrm{mg} . \mathrm{L}^{-1}\right)$ foi determinada pelo método Gravimétrico, utilizando-se cápsula de porcelana, disco de microfibra de vidro, balança eletrônica de precisão, estufa a temperatura de $120{ }^{\circ} \mathrm{C} \quad \mathrm{e}$ dissecador/Pyrex $/ / 200 \mathrm{~mm}$. Idem para a fonte.

As análises de Coliformes Totais (mg. $\mathrm{L}^{-1}$ ) e Coliformes Fecais (NMP/100mL) foram realizadas por meio do método de contagem de Escherichia coli a partir de Placas Petrifilm em Estufa de Cultura.

$\mathrm{Na}$ construção da fórmula paramétrica para calcular o IQA, foram estabelecidas curvas de variação da qualidade das águas de acordo com o estado ou a condição de cada um dos 09 parâmetros contemplados, assegurando um adequado grau de precisão através do uso individual ou combinado de funções lineares e não lineares segmentadas em faixas de consideração.

Para Bollmann e Marques (2000), a partir destas curvas de variação, sintetizadas em um conjunto de curvas médias para cada parâmetro, bem como seu 
peso relativo correspondente, é calculado o IQA. Ou seja, o IQA é o produtório ponderado das qualidades de água correspondentes aos parâmetros: temperatura da amostra, $\mathrm{pH}$, oxigênio dissolvido, demanda bioquímica de oxigênio ( 5 dias, $20{ }^{\circ} \mathrm{C}$ ), coliformes termotolerantes, nitrogênio total, fósforo total, sólido total e turbidez.

onde:

$$
I Q A=\prod_{i=1}^{n} q_{i}^{w_{i}}
$$

IQA: Índice de Qualidade das Águas;

qi: qualidade do i-ésimo parâmetro, um número entre 0 e 100, obtido da respectiva "curva média de variação de qualidade", em função de sua concentração ou medida e;

wi: peso correspondente ao i-ésimo parâmetro, um número entre 0 e 1 , atribuído em função da sua importância para a conformação global de qualidade, sendo que:

$$
\sum_{i=1}^{n} w_{i}=1
$$

em que:

n: número de parâmetros que entram no cálculo do IQA.

No caso de não se dispor do valor de algum dos 9 parâmetros, o cálculo do IQA é inviabilizado.

A partir do cálculo efetuado, pode-se determinar a qualidade das águas brutas indicada pelo IQA numa escala de 0 a 100 (Tabela 1).

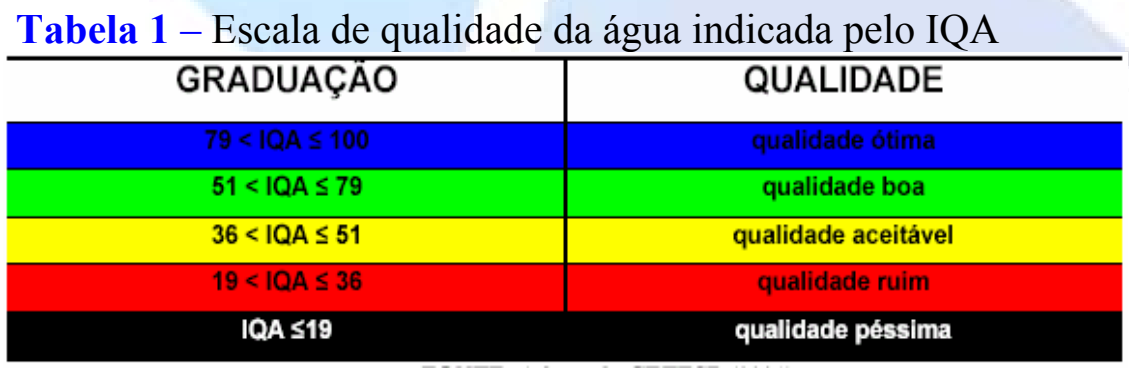

Fonte: CETESB (2004)

Para verificação dos parâmetros analisados no laboratório, este trabalho toma como base de referência a Resolução do Conselho Nacional do Meio Ambiente Resolução CONAMA nº 357, de 17 de março de 2005 (BRASIL, 2005). 


\section{RESULTADOS E DISCUSSÃO}

Nas Figuras 3 a 9 se encontram os valores calculados do IQA para os sete pontos estudados. O ponto 1 apresentou a melhor qualidade de água dentre os pontos (média de 46,7), sendo identificado como água de qualidade "Aceitável”. Esperava-se que a qualidade da água fosse no mínimo "Boa" por tratar-se de uma nascente e estar localizada antes da região urbanizada, porém acredita-se que a influência da zona rural ou a sua própria característica natural tenha determinado essa qualidade de "Aceitável".

O ponto 2 teve qualidade de água, com classificação média "Ruim" (média de 34,6 ), pois neste local já houve influência da área urbana, provavelmente pela existência de fossas sépticas ou pelas obras realizadas em Agosto de 2007, ambas próximas a nascente; observou-se que os meses de Agosto e Setembro apresentaram os dois piores resultados, influenciando a média (Figura 4).

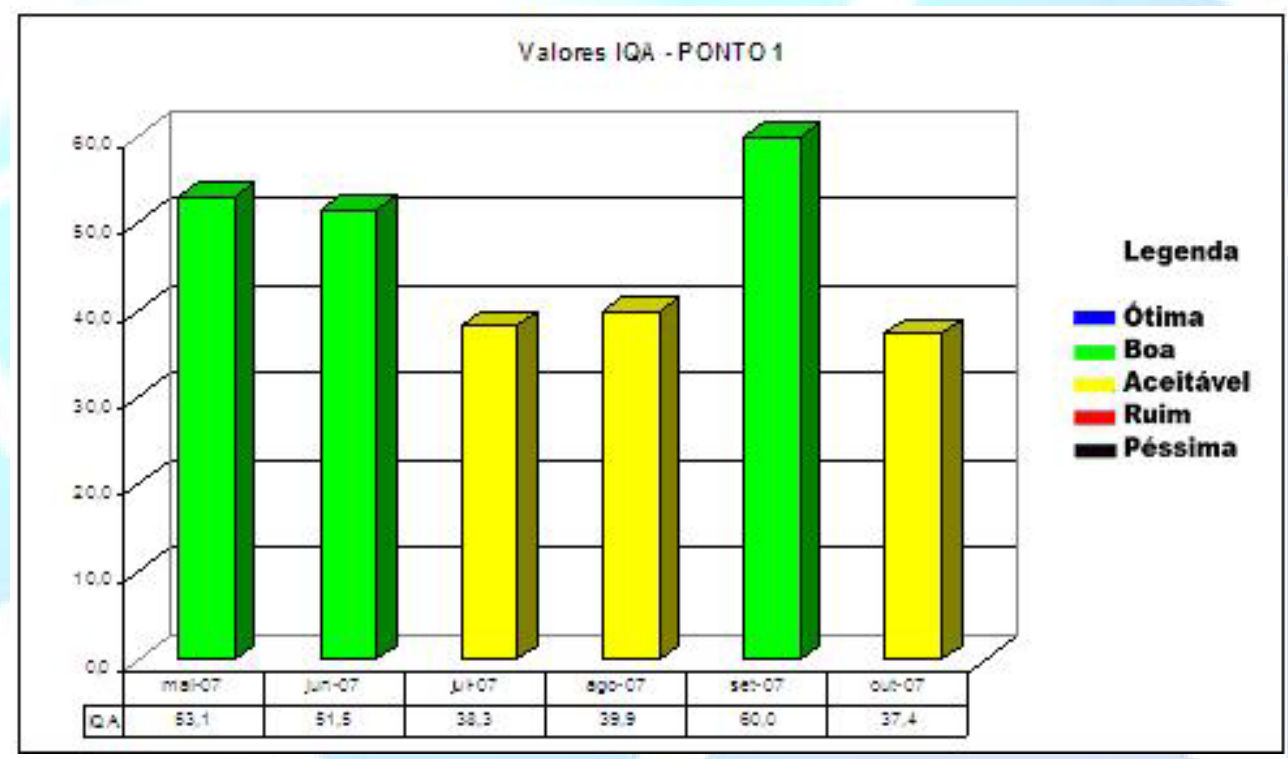

Figura 3. IQA do Ponto 1, no período de maio a outubro de 2007, localizado na Microbacia Hidrográfica do Córrego Gavanhery, Getulina - SP 


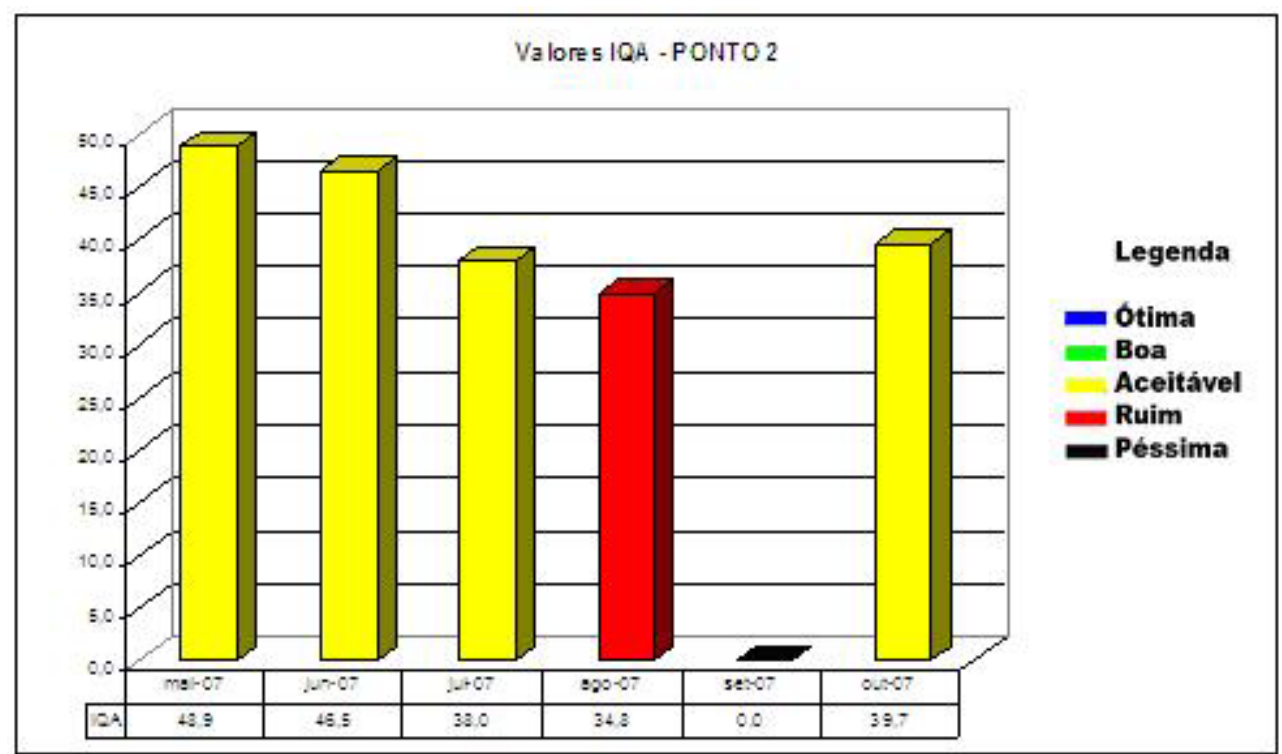

Figura 4. IQA do Ponto 2, no período de maio a outubro de 2007, localizado na Microbacia Hidrográfica do Córrego Gavanhery, Getulina - SP

O ponto 3, teve a qualidade de água classificada como "Aceitável" (média de 40,1). Este resultado destoa daquilo que normalmente se esperava, pois, esse ponto recebeu contribuição clandestina de esgoto doméstico, lançamento de resíduos sólidos em sua margem, influência da zona rural e era dotado de pouca mata ciliar (Figura 5).

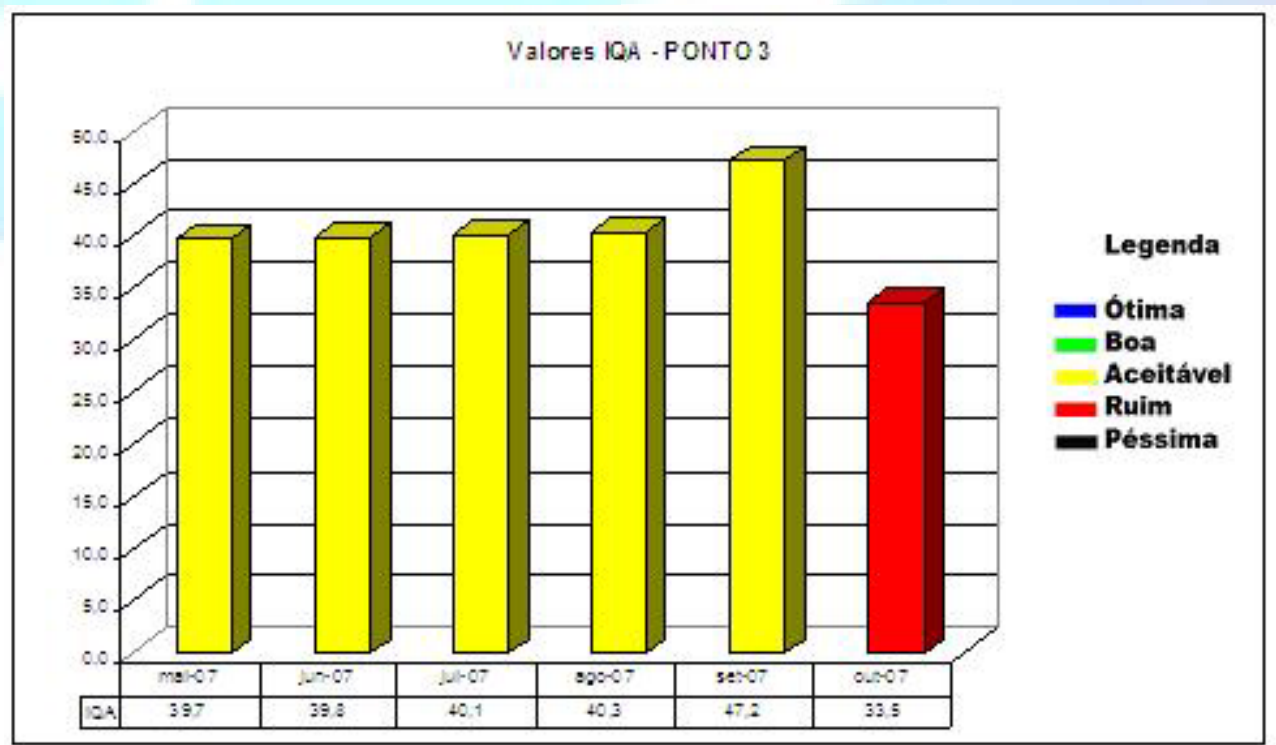

Figura 5. IQA do Ponto 3, no período de maio a outubro de 2007, localizado na Microbacia Hidrográfica do Córrego Gavanhery, Getulina - SP

O ponto 4 por sua vez, que está localizado a jusante do cruzamento dos Córregos Gavanhery e Lambari apresentou qualidade de água com classificação "Ruim" (média de 35,0), pois esse ponto recebe toda a carga poluidora dos dois 
Córregos (Figura 6). Apesar do ponto 3 estar localizado próximo ao ponto 4, os resultados da qualidade da água apresentaram-se bem diferentes. O ponto 4 está além do perímetro urbano, porém sofre grandes influências da área urbana. Em suas proximidades não existe mata ciliar e o assoreamento é enorme. Cuelbas (2009), na determinação do IQA para o Córrego Campestre na cidade de Lins-SP, constatou que este se altera negativamente na época de chuvas, com aumento nas concentrações de alguns parâmetros como, por exemplo, turbidez, fósforo e sólidos totais. Estudos realizados na microbacia do Córrego do Ipê (POLETO et al., 2010) indicaram sua degradação, com avançado estado de assoreamento em praticamente toda sua extensão devido à pequena quantidade de matas ciliares e ao mau uso do solo.

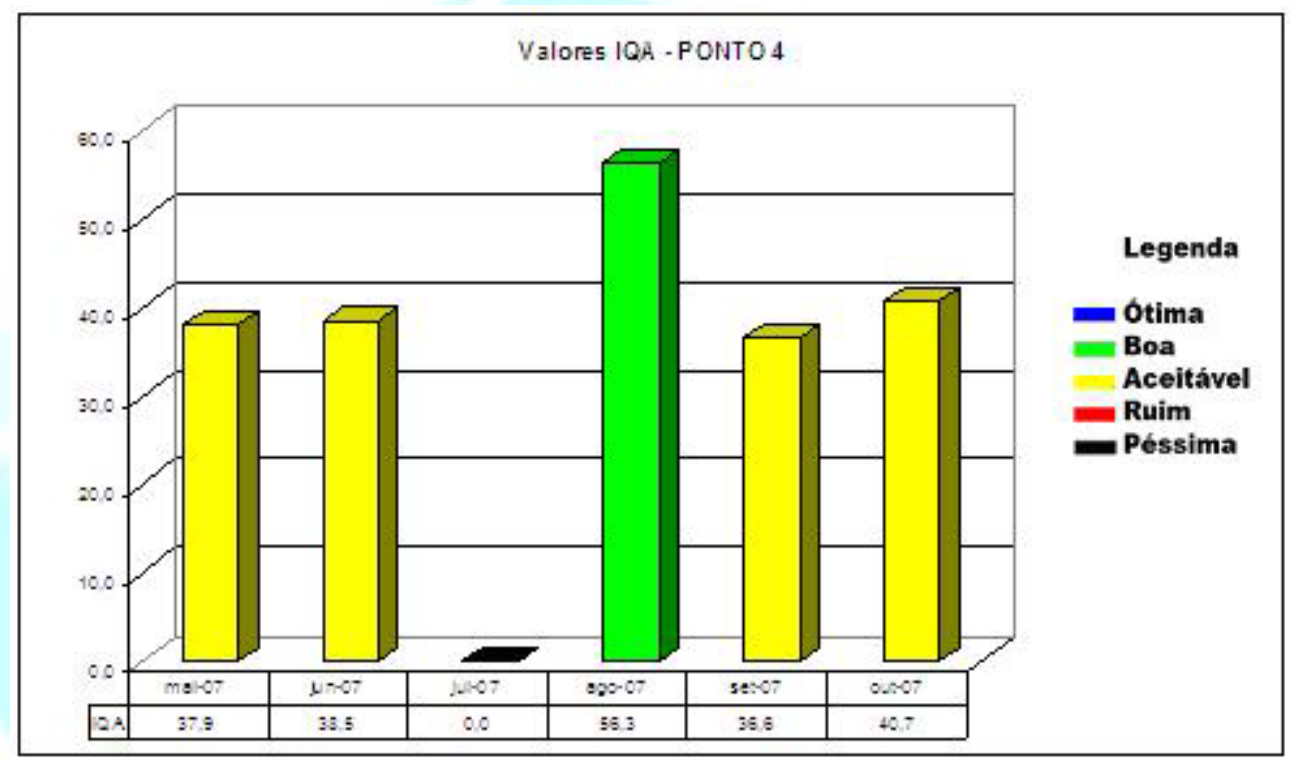

Figura 6. IQA do Ponto 4, no período de maio a outubro de 2007, localizado na Microbacia Hidrográfica do Córrego Gavanhery, Getulina - SP

Viveiros (2009) analisou a água do Córrego Campestre, que atravessa a cidade de Lins-SP em sete pontos e constatou que os valores de IQA encontrados variaram entre 18,1 a 50,2, estando classificada entre péssima a aceitável, com classificação média "Ruim" $(33,2)$.

O ponto 5 está localizado a 15,0 metros do lançamento da ETE e obteve qualidade de água com a classificação "Ruim" (35,2) (Figura 7). Este ponto está localizado depois da área urbanizada e além da influência da ETE possui influência da zona rural. Pode-se observar que, apesar da ETE atender aos padrões de lançamento de efluentes domésticos em córrego de classe 2, ela influencia negativamente na qualidade da água.

A mesma constatação foi feita por Viveiros (2009) no ponto 4 do Córrego Campestre em Lins que foi o mais crítico de todos, com média de 18,0 de IQA, apresentando classificação "Péssima", fato este ligado possivelmente a ETE e/ou o antigo lixão da cidade. 
O ponto 6 teve qualidade de água, com classificação "Aceitável" (média de 40,9) (Figura 8), sofrendo influência principalmente da zona rural, com o cultivo de cana de açúcar e gado de corte. Embora o escopo deste trabalho não seja o de análise de autodepuração, percebe-se que houve uma melhoria da qualidade da água entre os pontos 4 a 6 .

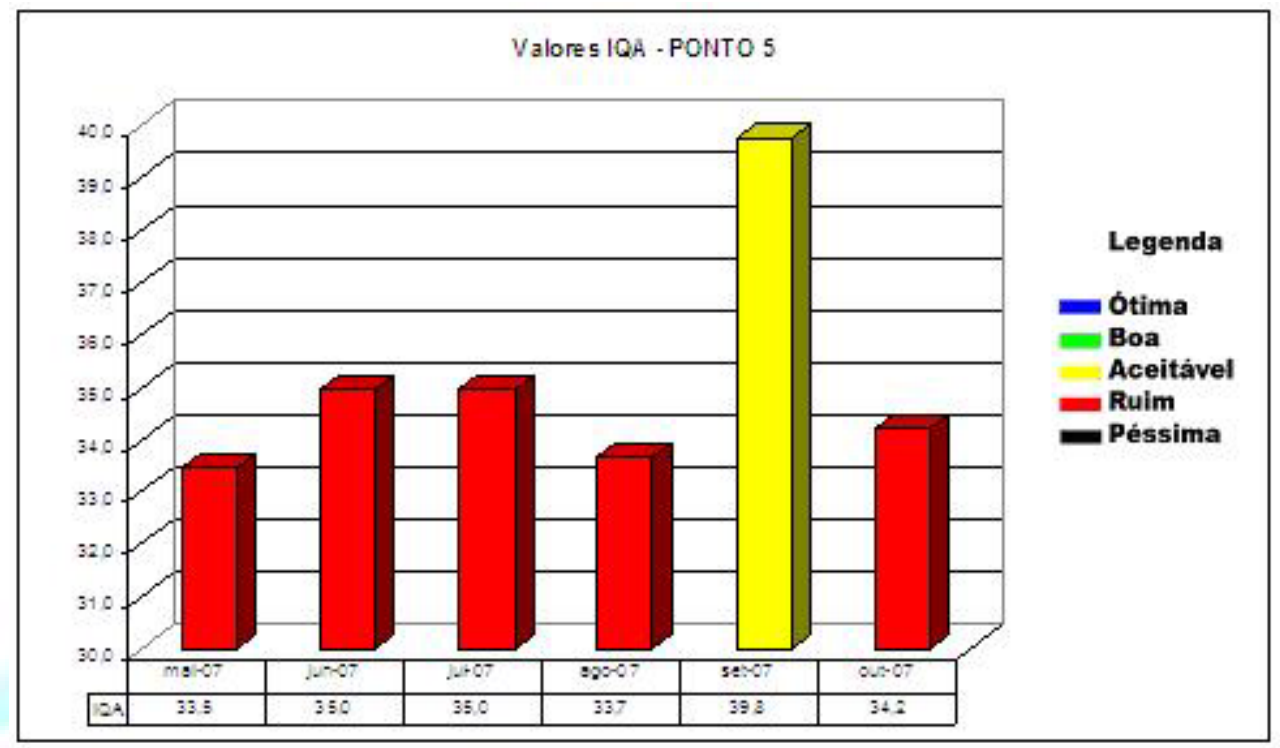

Figura 7. IQA do Ponto 5, no período de maio a outubro de 2007, localizado na Microbacia Hidrográfica do Córrego Gavanhery, Getulina - SP

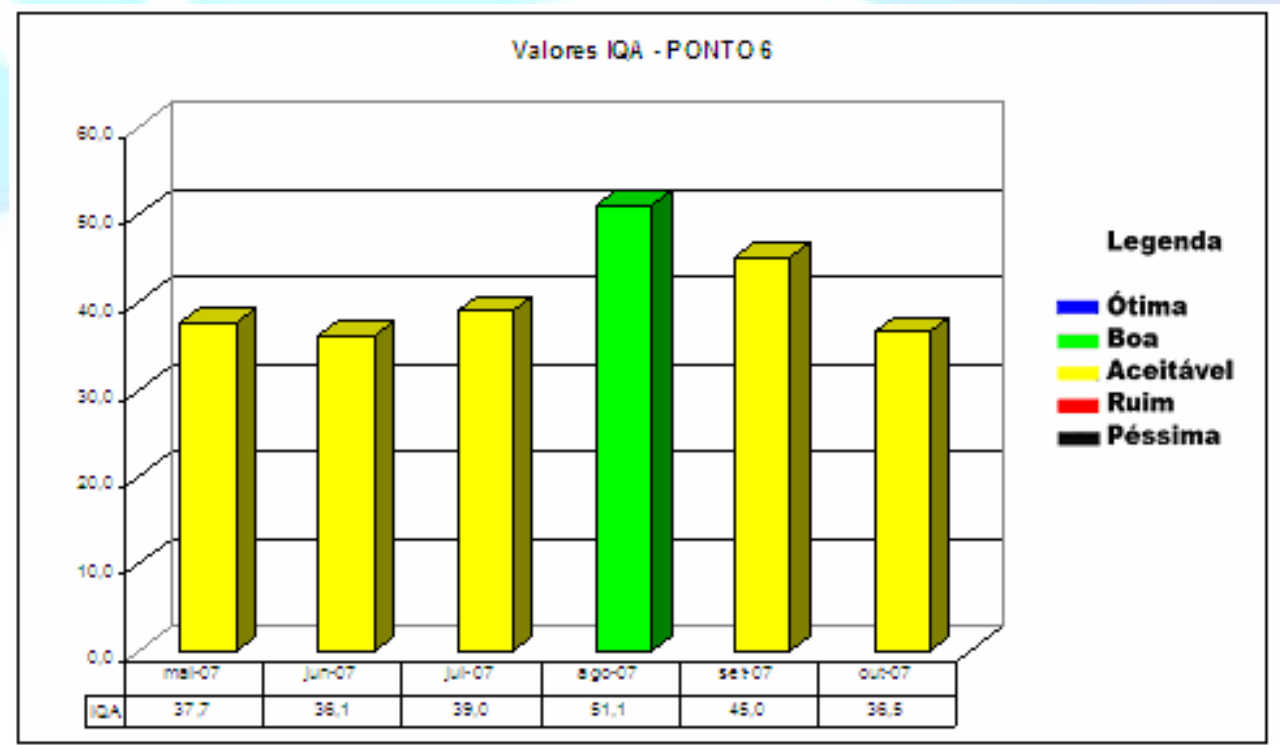

Figura 8. IQA do Ponto 6, no período de maio a outubro de 2007, localizado na Microbacia Hidrográfica do Córrego Gavanhery, Getulina - SP

O ponto 7 (Figura 9), por ser o exutório da microbacia, sofre a influência direta dos outros pontos, que são afetados por descargas orgânicas ou inorgânicas. A 
qualidade de água, para esse ponto obteve classificação "Aceitável" (média de 34,6). Percebe-se, portanto, que a qualidade da água do ponto $6(\mathrm{IQA}=40,9)$ para o ponto 7 (IQA=45,1) ficou praticamente estável apesar do aumento significativo. Ressalta-se ainda que o ponto 7 sofreu grande influência da zona rural com a criação de gado de corte, apesar de possuir uma grande área de mata ciliar em suas proximidades.

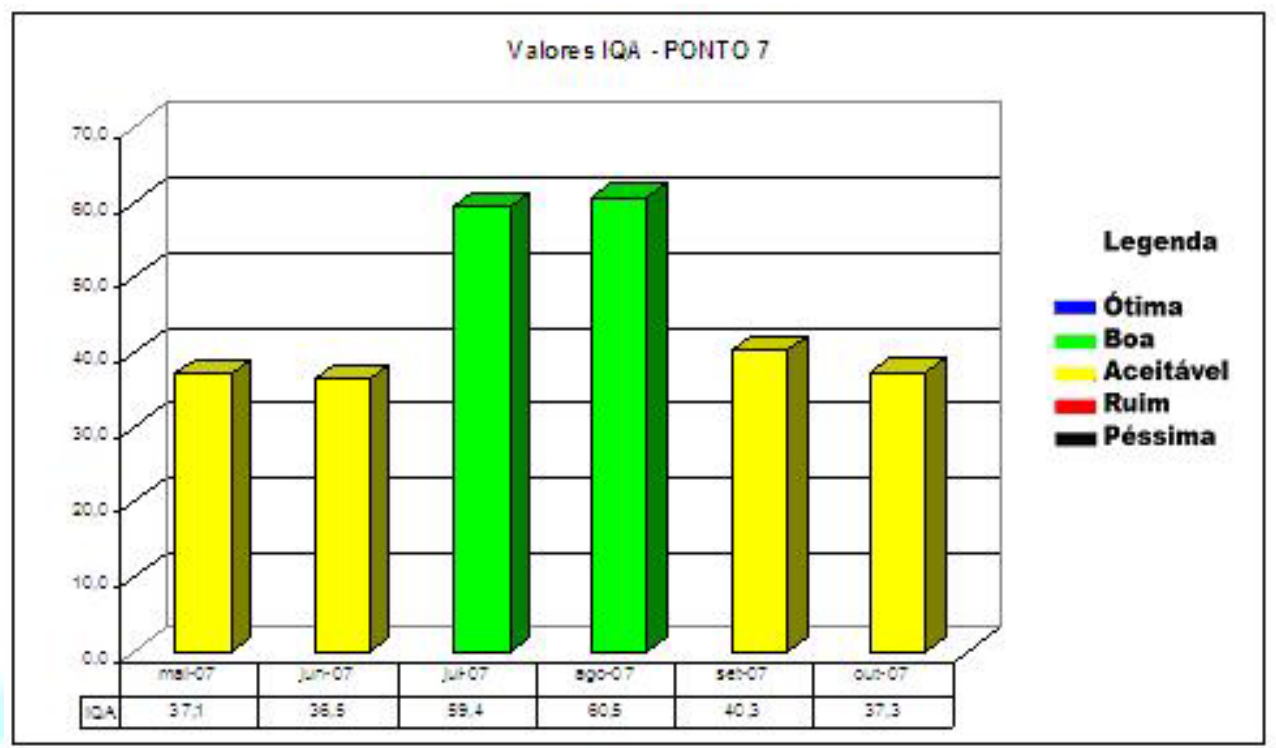

Figura 9. IQA do Ponto 7, no período de maio a outubro de 2007, localizado na Microbacia Hidrográfica do Córrego Gavanhery, Getulina - SP

Resumindo, os valores de IQA variaram de 34,6 (Ruim) para o ponto 2 a 46,7 (aceitável) para o ponto 1 . Dos sete pontos estudados, três apresentaram valores de IQA que se enquadram na classificação "Ruim" (pontos 2, 4 e 5) enquanto que os demais pontos $(1,3,6$ e 7) se enquadram na classificação apenas "Aceitável".

As atividades da zona urbana causadoras de impactos significativos que reduziram os valores de IQA podem ser caracterizadas pela existência de fossas sépticas e ausência de matas ciliares (ponto 2) lançamento de esgotos clandestinos, de resíduos sólidos na margem e pequena quantidade de matas ciliares (ponto 3), falta de práticas de conservação do solo, avançado estado de assoreamento, ausência de matas ciliares, elevada turbidez, e altas concentrações de fósforo e sólidos (ponto 4), ineficiência da ETE (ponto 5).

As atividades da zona rural que causaram impactos importantes aos mananciais foram o cultivo de cana de açúcar e gado de corte (pontos 1, 6 e 7).

\section{CONCLUSÕES}

Os resultados obtidos neste estudo com base nos testes de IQA e visitas "in loco" permitiram concluir que existe elevado impacto das atividades antrópicas na qualidade das águas dos Córregos Gavanhery e Lambari, levando a intensa degradação desses mananciais. 
Os valores obtidos para a qualidade da água são inferiores aos de um rio de classe 2, com destaque para o Ponto "5", situado no meio urbano, localizado a 15,0 metros a jusante do lançamento da ETE que obteve os piores resultados, isto é cinco das seis amostragens com classificação "Ruim".

Os baixos índices encontrados nos valores do IQA dos mananciais estudados devem-se ao impacto das atividades antrópicas desenvolvidas na zona urbana (pontos 2, 3, 4 e 5), assim como na área rural (pontos 1, 6 e 7).

Os resultados obtidos demonstram que a má qualidade dos recursos hídricos dos Córregos Gavanhery e Lambari acabarão comprometendo as populações futuras que dependem da boa qualidade da água, caso medidas drásticas não sejam tomadas.

Dessa forma, espera-se que os resultados obtidos neste trabalho, possam ter contribuído com importantes informações que possam fornecer subsídios para o desenvolvimento de novos projetos que visem um melhor conhecimento e a preservação de forma sustentável desta microbacia e dos recursos naturais desta região.

\section{REFERÊNCIAS}

BASSO, E.R.; CARVALHO, S.L. Avaliação da Qualidade da Água em duas represas e uma lagoa no município de Ilha Solteira - S.P. Holos Environment, v.7, n.1, p.1629, 2007.

BOLLMANN, H.A.; MARQUES, D.M. Bases para a estruturação de indicadores de qualidade de águas. RBRH - Revista Brasileira de Recursos Hídricos, São Paulo, v.5, n.1, p.37-60, 2000.

BRANCO, S.M. A água e o homem. In PORTO, R.L.L.; BRANCO, S.M.; CLEARY, R.W.; COIMBRA, R.M.; EIGER, S.; LUCA, S.J. de; NOGUEIRA, V. De P.Q.; PORTO, M.F. do A. Hidrologia ambiental. Editora da Universidade de São Paulo: Associação Brasileira de Recursos Hídricos. v.3. 1991. 414p.

BRASIL. Ministério do Meio Ambiente. Conselho Nacional do Meio Ambiente. Resoluções do CONAMA nº. 357. (5ed). Brasília, DF. SEMA, 2005. 23 p.

CALIJURI, M.C.; OLIVEIRA, R. Manejo da qualidade da água: uma abordagem metodológica. In: CASTRO, R. et al. Desenvolvimento sustentado: problemas e estratégicas. $1^{\text {a }}$ Edição. São Carlos: EESC-USP, 2000. v.1, cap 1, p. 39-58.

CETESB - COMPANHIA ESTADUAL DE TECNOLOGIA DE SANEAMENTO BÁSICO. Relatório da qualidade das águas interiores do Estado de São Paulo 2003. São Paulo: CETESB, 2004. 264 p. 
CLESCERI, L.S.; GREENBERG, A.D.; EATON, A.D. (Ed.) Standard methods for the examination of water and wastewater. 20.ed. Washington: American Public Health Association 1998.

CUELBAS, L.P.; CARVALHO, S.L. Avaliação da Qualidade da Água na Microbacia do Córrego Campestre no Município de Lins (SP), Holos Environment, v.9, n.1, p.14-30, 2009.

IBGE - INSTITUTO BRASILEIRO DE GEOGRAFIA E ESTATÍSTICA. Tabela População residente, por sexo e situação do domicílio, população residente de 10 anos ou mais de idade, total, alfabetizada e taxa de alfabetização, segundo os Municípios -2000 .

MEYBECK, M.; HELMER R. An introduction to water quality In: CHAPMAN, D. Water quality assessment. Cambridge, University Press, 1992. 585p.

PIELOU, E.C. Freshwater. Chicago: The University of Chicago Press, 1998, p. 275.

POLETO, C.; CARVALHO, S.L.; MATSUMOTO,T. Avaliação da qualidade da água de uma microbacia hidrográfica no município de Ilha Solteira (SP). Holos Environment, v.10, n.1, 2010.

REFOSCO, J. C. Ecologia da Paisagem e Sistema de Informações Geográficas no Estudo da Interferência da Paisagem na Concentração de Sólidos Totais no Reservatório da Usina de Barra Bonita - SP. São Carlos, 1996. 129 f. Dissertação (Mestrado em Ciências da Engenharia Ambiental) - Escola de Engenharia de São Carlos, Universidade de São Paulo. São Carlos, SP, 1996.

RODRIGUES JR., F. Diagnóstico da Influência de Atividades Antrópicas na Qualidade da Água do Córrego Gavanhery no Município de Getulina - SP. 2008. 94 f. Dissertação (Mestrado em Engenharia Civil) Faculdade de Engenharia de Ilha Solteira, Universidade Estadual Paulista. Ilha Solteira,SP, 2008.

TUNDISI, J.G. Água no século XX: enfrentando a escassez. 2.ed. São Carlos: Rima, 2003. 264 p.

VIVEIROS, J.I.A. Capacidade de auto-recuperação de cursos d'água urbanos. Estudo de Caso: Córrego Campestre, em Lins - SP. 2009. 163 f. Dissertação (Mestrado. em Engenharia Civil) Faculdade de Engenharia de Ilha Solteira, Universidade Estadual Paulista. Ilha Solteira, SP, 2009. 